DOI: $10.35355 / 0000044$

\title{
A ANTROPOÉTICA DE BRUNO DE MENEZES
}

\author{
Rodrigo de Souza Wanzeler* \\ Instituto Federal de Educação, Ciência e Tecnologia do Pará - IFPA \\ rodrigo.wanzeler@ifpa.edu.br
}

\begin{abstract}
RESUMO: Tomando Belém como cenário principal para o contexto deste trabalho, tem-se, com o apogeu da comercialização da borracha e a criação do Museu Paraense, um incremento científico na região, que almejava ser a Paris na Amazônia. Neste período, Belém vai do ápice à crise da comercialização da goma elástica, turbulências sociais tornam-se mais frequentes e as desigualdades latentes. Este contexto não passa impune ao olhar de Bruno de Menezes. O intelectual se vale da sua escrita, artística e politicamente engajada, para desvelar e se opor ante as diferenças sociais. Uma escrita de rexistência que, assim como a ciência antropológica no mesmo período, busca dirimir as discrepâncias existentes no cotidiano das sociedades amazônicas. Desta maneira, a presente pesquisa intenta relacionar os caminhos da ciência antropológica com os de Bruno de Menezes para incluir o nome do intelectual belenense enquanto figura importante para a consolidação de um fazer antropológico na/da Amazônia.
\end{abstract}

PALAVRAS-CHAVE: História da Antropologia - Literatura - Amazônia - Bruno de Menezes.

\section{THE BRUNO DE MENEZES'S ANTHROPOETICS}

\begin{abstract}
Taking Belém as the main scenario for the context of this work, we have, with the heyday of the commercialization of rubber and the creation of the Museu Paraense, a scientific increase in the region, which aspired to be Paris in the Amazon. In this period, Belém goes from the apogee to the crisis of the commercialization of elastic gum, social turbulences become more frequent and the inequalities more outpouring. This context was observed by the Bruno de Menezes eyes. The intellectual uses his writing, artistic and politically engaged, to unveil and oppose social differences. A rexistance writing that, like the anthropological science in the same period, aims to resolve the discrepancies existing in the daily life of Amazonian societies. In this way, this research attempts to relate the paths of anthropological science with those of Bruno de Menezes to include the name of the intellectual as an important figure for the consolidation of an anthropological work at/in the Amazon.
\end{abstract}

KEYWORDS: History of Anthropology - Literature - Amazon - Bruno de Menezes.

Professor EBTT do Instituto Federal de Educação, Ciência e Tecnologia do Pará; Doutor em Antropologia Social (PPGA-UFPA); Mestre em Estudos Literários (PPGL-UFPA); Graduado em Letras - Licenciatura em Língua Portuguesa e Língua Inglesa (UFPA). 


\section{INTRODUÇÃO}

Pensar a Antropologia enquanto uma ciência humana nos faz percorrer um longo caminho por grande parte da história da humanidade, não que ela tenha o status de ciência desde sempre, no entanto, algumas preocupações recorrentes na Antropologia dita científica remontam, por exemplo, aos tempos antigos, em que Heródoto, desde jovem um viajante do mundo grego, desvela em suas narrativas o olhar sobre o outro; passando pelo medievo; as grandes navegações e as conquistas europeias, em que os contatos interculturais se asseveraram; o Iluminismo, período em que se reforçou a visão do homem enquanto medida de todas as coisas; o Romantismo e sua verve nacionalista; até a institucionalização da Antropologia na academia.

Uma Antropologia próxima do que temos nos moldes atuais se desenvolveu de forma mais ampla ao longo do século XIX e início do XX, quando o exercício de percepção do outro e de si mesmo se uniu a um aspecto mais teórico, partindo da Europa para outras partes do mundo.

No Brasil, o surgimento da Antropologia se deu a priori sob um enfoque mais estritamente biológico e físico, a posteriori envolvendo também os âmbitos cultural, arqueológico e linguístico, sob a influência da Antropologia desenvolvida nos Estados Unidos. Apesar de, segundo Salzano (2009, p. 16), a participação de linguistas e bioantropólogos ser praticamente nula nos programas de Antropologia do Brasil, prevalecendo um grupo amplamente maior de antropólogos sociais ou culturais e, em menor número, de arqueólogos.

De início, nomes como Peter Lund e sua descoberta de material ósseo em Lagoa Santa; Barbosa Rodrigues; Nina Rodrigues; Curt Nimuendajú; Koch-Grünberg; Roquete-Pinto; Herman von Ihering, entre outros, têm destaque no pioneirismo dos estudos antropológicos no Brasil, que, para Salzano (2009, p. 17), delimita-se entre os anos de 1835, ano da descoberta acima citada de Lund, e 1933, ano anterior à fundação da Universidade de São Paulo (USP). Para além dos nomes supracitados, ainda na esteira do desenvolvimento da Antropologia, outro aspecto é de extrema relevância para a conformação dos estudos antropológicos no país: o surgimento dos museus etnográficos. 
A ideia contemporânea de museu surgiu na Europa nos séculos XVIII e, com mais intensidade, no XIX, fortemente marcada pela recuperação de uma memória que revigorasse o nacionalismo em diversos países, visto que o continente passava por uma espécie de refluxo no que tange às políticas imperialistas implantadas e desenvolvidas a partir das grandes navegações. Tais espaços (museus) surgiram como locais da memória, resguardando documentos que comprovariam os feitos de outrora, como por exemplo, o Arquivo Nacional, em França. No entanto, posteriormente se tornaram locais dedicados ao colecionismo, ao estudo, interpretação e preservação de objetos da cultura material, daí serem chamados, de acordo com Schwarcz (2010, pp. 68-69) de museus etnográficos.

O primeiro grande exemplo desse tipo de museu é o British Museum, fundado em 1753, na Inglaterra. Já no século XIX, tem-se o Museu Etnográfico de Ciências de São Petersburgo, Rússia, de 1836, e o National Museum of Ethnology, em Leiden, Holanda, de 1837. Fora do eixo europeu, o museu de maior relevância foi o Peabody Museum of Archeology and Ethnology, nos Estados Unidos, fundado em 1866. Daí em diante, os museus que surgiram mundo afora foram influenciados tanto pelo Peaboby, no que tange à pré-história, à arqueologia e à etnologia, quanto pelos museus europeus, caracterizados como centros das suas respectivas culturas nacionais.

No Brasil, o século XIX foi marcado pelo surgimento de grandes museus que objetivavam, a priori, principalmente, os estudos de zoologia e botânica nos respectivos espaços em que foram idealizados, além do intercâmbio de informações com os centros estrangeiros. Entretanto, mais tarde estes espaços serviriam como locus para os estudos voltados para uma Antropologia nascente. Os principais museus brasileiros do século XIX são: Museu Nacional, no Rio de Janeiro; Museu Paulista, em São Paulo; e Museu Paraense, em Belém.

O Museu Nacional foi fundado em 1808, coincidindo sua fundação com a chegada da família real ao Brasil. Trazia em seu bojo coleções doadas por Dom João VI, mas que ainda deixavam o MN longe do que eram já naquele contexto os museus europeus e estadunidenses. Somente a partir da década de 1870 que o MN iniciou um processo maior de inserção no meio científico, principalmente, a partir da criação da revista Archivos do Museu Nacional, em 1876, que continha artigos relacionados às áreas de Botânica, Zoologia - estas duas as áreas mais representativas neste contexto Geologia, Antropologia e Arqueologia. Sendo que em seu primeiro número, a revista 
trazia três artigos de Antropologia, entre eles a proposição de João Batista Lacerda sobre os estudos dos Botocudos, mas sob uma ótica mais físico-biológica do que social, justamente pela influência contextual das ciências naturais. Lacerda foi, nesse sentido, o responsável pelo primeiro curso de Antropologia no país, oferecido em 1877, de base puramente biológica, mas que serviu de alicerce no desenvolvimento científico do ramo antropológico no Brasil.

Em São Paulo, no ano de 1885, surge o Museu do Ypiranga, caracterizado mais como um monumento comemorativo, alusivo à Independência, do que como uma instituição científica. Em 1894, já com algumas coleções disponíveis, inaugura-se oficialmente o Museu Paulista, com o objetivo enciclopédico de reunir, pretensamente, todo o conhecimento produzido pelo homem até então. Na década de 1890, o nome de Herman von Ihering se liga diretamente ao desenvolvimento deste museu, imprimindolhe um perfil profissional no que tange à pesquisa semelhante aos modelos europeus. Assim como no Museu Nacional, uma revista trouxe um ar de cientificidade ao MP, a Revista do Museu Paulista. Idealizada por von Ihering, a revista trazia em seu bojo textos relacionados às seguintes áreas: Botânica, Zoologia, Geologia, Antropologia, Arqueologia, Biografias e Diversos. A Zoologia dominou os escritos da revista por mais de trinta anos. Por coincidência, Zoologia era a área de atuação de von Ihering, o que comprova as marcas personalistas impressas por ele na referida revista. Nesse sentido, a Antropologia teve seu pequeno espaço dentro do Museu Paulista, ainda bastante influenciada pelas ciências naturais, mas que também contribuiu para o assentamento desta área enquanto ciência no Brasil.

Outro museu de extrema importância a ser abordado, para o contexto do desenvolvimento da Antropologia no Brasil entre os séculos XIX e XX, é o Museu Paraense, que posteriormente passou a ser chamado de Museu Paraense Emílio Goeldi. No entanto, como o propósito deste trabalho engloba o desenvolvimento da Antropologia e do fazer antropológico na Amazônia paraense, na tentativa de inserir neste contexto o nome de Bruno de Menezes, abordar-se-á o referido museu, de forma mais específica, no tópico a seguir.

\section{A ANTROPOLOGIA DA/NA AMAZÔNIA: A IMPORTÂNCIA DO MUSEU PARAENSE EMÍLIO GOELDI}


Ao longo da história, a Amazônia foi concebida enquanto um espaço mágico, povoado por seres encantados, o que despertava a curiosidade de diversos viajantes. Este imaginário criado sobre a região desvela uma relação histórica peculiar. A Amazônia foi, primordialmente, criada por outros, os discursos sobre a região, historicamente, possuem uma perspectiva centrípeta, ou seja, de fora para dentro, distorcendo a imagem amazônica e/ou criando um paraíso perdido no sertão brasileiro. Ou seja, as duas imagens da Amazônia, positiva e negativa, geraram e enraizaram diferentes tipos de discurso sobre a região. Acerca da questão discursiva sobre a Amazônia, Ana Pizarro afirma que

El período de la ocupación de la Amazonía, entre los siglos XV e fines del XVIII e incluso primera parte del XIX, está marcado por un fuerte discurso europeo. Primero están los "descubridores", los ocupantes, luego los viajeros científicos. Entre los primeros está también el discurso misionero. El territorio es ocupado físicamente, pero se penetra apenas hacia el interior desde las orillas de los rios, afluentes, de los igarapés. El territorio es inexpugnable, la selva es como una gran muralla, sobre la que se tejen multitud de histórias. La Amazonía $^{l}$ es ocupada sobre todo por la imaginación (PIZARRO, 2005, p.134). [destaque nosso]

Devido ao tipo de ocupação feita na região amazônica, não permitindo, tão logo, a entrada dos exploradores na mata ao entorno dos rios, iniciou-se a construção de um imaginário devido ao temor e, ao mesmo tempo, à atração pelo desconhecido. Franceses, holandeses, portugueses, espanhóis, ingleses, entre outros, foram uns dos principais navegadores que vieram para estes lados. A Amazônia começara a partir de então a se tornar o equivalente ocidental das Índias na América. Nomes como os de Vicente Yánes Pinzon, Pedro de Anzures, Gonzalo Pizarro, Francisco Orellana, Pedro Teixeira, Pedro de Urzúa, Ambrosio de Alfinger, Philip von Hutten e Walter Raleigh estão entre os pioneiros no que diz respeito ao desbravamento da Amazônia pelas matas e rios, a partir do século XVI (PIZARRO, 2012, p. 38).

Os relatos de viajantes, exploradores e/ou missionários, admirados com tamanha proporção da mata e dos rios, causavam temor, mas também despertavam a fantasia em quem os lia ou os ouvia. Como afirma Pizarro ao final da passagem

1 A Amazônia de Pizarro engloba oito nações soberanas: Brasil, Venezuela, Colômbia, Equador, Peru, Bolívia, Suriname, Guiana Inglesa e Guiana Francesa, seria a Panamazônia, faixa geograficamente e climaticamente semelhante. 
anteriormente citada "A Amazônia é ocupada, sobretudo, pela imaginação". Nesse sentido, ao longo de sua história, a Amazônia foi concebida, paradoxalmente, como uma espécie de inferno paradisíaco.

No século XX, Euclides da Cunha, escritor brasileiro, representou este paradoxo histórico inerente à Amazônia. No livro Um paraíso perdido o autor faz reflexões sobre o espaço amazônico, semelhante ao que fez n'Os Sertões em relação ao nordeste brasileiro. Naquele livro, o título de um capítulo nos chama atenção, $O$ Inferno Verde, literalmente, o inferno contido no paraíso. Neste sentido, Pizarro reflete sobre a colonização da Amazônia afirmando que:

Así fue construyéndose la primera imagen de la Amazonía: espacio paradisíaco e infernal, poblado de seres aptos para su transformación em siervos de la Iglesia Católica, que habitan um espacio poblado de riquezas a considerar y de seres que pertenecen a uma zoologia fantástica. Un mundo endemoniado proclive a la locura. Es así como se construyó el primer discurso, ampliamente difundido através de las crônicas, relaciones y escritos de viaje, formando parte de uma literatura geográfica, estímulo para cualquier forma de la imaginación europea, fuese ella erótica, social o comercial (PIZARRO, 2005, p. 140).

Como diz a própria Pizarro, esta seria a primeira imagem construída da Amazônia, ou seja, há outras. Para a autora, o discurso dos séculos XVIII e XIX é racional e explorador, respectivamente, em comparação à época da colonização da região. No entanto, apesar das mudanças, a construção discursiva sobre a Amazônia é marcada, essencialmente, pela contradição, e isto se estende ao longo da história.

$\mathrm{Na}$ linha da existência de outras imagens discursivas acerca da Amazônia, para além do que é essencialmente imaginado, há a forte presença, nos séculos XVIII e XIX, de um discurso de base cientificista: o dos chamados naturalistas. Nomes como La Condamine, Condreau, Agassiz, Humboldt, Wallace e Bates são um dos mais relevantes no que diz respeito às explorações/missões vindas para a Amazônia a partir do século XVIII. Tempo em que o discurso mítico dos observadores se mescla a um pensamento racional, cientificista que logrou êxito após o Iluminismo.

A vinda dessas pessoas para terras Amazônicas fez parte, não apenas de uma busca pelo conhecimento, mas também, de um projeto político mais amplo de dominação oriundo nas metrópoles que as enviara. O pensamento ilustrado reforçara desta maneira a ideia eurocêntrica de controle dos outros. Nesse sentido, pode-se 
afirmar que o surgimento no Brasil dos museus etnográficos, como o Paraense, segundo Ferreira (2009, p. 72), coadunava com as políticas coloniais.

É neste contexto viajero que surge, no século XIX, o Museu Paraense, um dos principais museus etnográficos no país, localizado na Amazônia, região então conhecida como o "paraíso dos naturalistas". O esforço de intelectuais sitiados em Belém, norteados por Domingos Ferreira Pena, originou em 1866 a Associação Filomática do Pará, com o intuito de se estudar a fauna, a flora, a geografia e a história da região amazônica, na tentativa de suprir a ausência de uma instituição de ensino superior. Como afirmam Oliveira \& Furtado:

Desde sua criação, em 1866, a Sociedade Philomática (denominada Museu Paraense em 1870, Museu Goeldi em 1901 e Museu Paraense Emílio Goeldi após 1931) tem contribuído para ampliar os conhecimentos antropológico, arqueológico e linguístico sobre a Amazônia (OLIVEIRA; FURTADO, 1995, p. 103).

Assim como os museus Nacional e o Paulista, o Museu Paraense passou por diversos problemas nas décadas de 1870 e 1880, principalmente com a perda de pesquisadores visto que os recursos financeiros eram escassos. Na década posterior, mais precisamente em 1891, durante o governo de Justo Chermont, o museu é reinaugurado, aproveitando-se a conjuntura financeira favorável por conta da crescente comercialização da borracha, e tendo Belém - enquanto pretensa referência citadina no Brasil, uma Paris na América - como principal polo de exportação do látex. No entanto, a carência de pesquisadores, de verbas e de um foco para a instituição ainda eram questões a serem resolvidas.

Os problemas começaram a ser dirimidos a partir de 1894, quando o então governador Lauro Sodré, sabendo da demissão de um pesquisador no Museu Nacional, contrata-o para o quadro do Museu Paraense. Tratava-se do zoólogo suíço Emílio Goeldi. A chegada de Goeldi ao Museu representou, segundo Schwarcs (2010, p. 85), a busca por torná-lo "uma reprodução fiel das instituições congêneres europeias", para tanto, Goeldi, que tinha contato com uma série de pesquisadores, traz para Belém diversos naturalistas estrangeiros, além de possibilitar a criação e publicação de revistas para divulgar as pesquisas realizadas no Museu. As revistas criadas foram o Boletim do Museu Paraense e Memória do Museu Paraense. 
Com base nos estudos de Schwarcs (2010, p. 88), observa-se que o Boletim continha, na primeira metade do século XX, trabalhos das seguintes áreas: Botânica, Zoologia, Geologia e Antropologia, com maior destaque à Zoologia, área de formação de Goeldi, com mais de sessenta trabalhos, e menor relevância à Antropologia, com apenas sete publicações, e à Arqueologia, a qual existia no Museu enquanto área de estudo, mas que não foi materializada em trabalhos para a revista até 1949.

O Museu Paraense cumpriu neste contexto o papel de tornar a Amazônia internacionalizada. A instituição era uma espécie de parada obrigatória aos pesquisadores e pesquisadoras vindos de outros países para a Amazônia brasileira. Além disso, o referido Museu, sob as rédeas de Goeldi, permaneceu focado mais no que se produzia internacionalmente do que localmente, visto que muito do que foi publicado neste período vinha de fora do país.

Apesar da pouca relevância, em termos de trabalhos publicados, dada à Antropologia e à Arqueologia, a gestão de Goeldi no comando do Museu Paraense teve como marca, de acordo com Oliveira \& Furtado (1995, p. 103), o incentivo aos estudos antropológicos e arqueológicos, sendo estes últimos importantes, inclusive, para a resolução de problemas territoriais envolvendo o Brasil e a França no que tange ao atual estado do Amapá, no fim do século XIX. Goeldi juntamente com Aureliano Guedes estudaram sítios arqueológicos nesta região, fato que trouxe grandes contribuições para a chamada arqueologia amazônica e respaldou Goeldi a intervir na querela supracitada, auxiliando na manutenção do que é hoje Amapá como parte do Brasil.

Ainda de acordo com Oliveira \& Furtado, para além desses estudos, o Museu contou com a aquisição de materiais e também com doações para o acervo,

Este é o caso, por exemplo, da coleção de 502 peças doada ao Museu Paraense por Theodor Koch- Grünberg - pesquisador alemão que viajou pelo noroeste da Amazônia entre 1903 e 1905, a serviço do Museu Etnográfico de Berlim, constituindo um riquíssimo acervo sobre os povos indígenas do alto rio Negro - em retribuição ao apoio recebido por parte de Emílio Goeldi (OLIVEIRA; FURTADO, 1995, p. 104).

Ao longo da primeira metade do século XX diversos pesquisadores e pesquisadoras contribuíram para a consolidação dos estudos antropológicos/arqueológicos na Amazônia e tiveram seus nomes inevitavelmente ligados ao Museu Paraense, ou melhor, ao já chamado Museu Goeldi. Oliveira \& 
Disponível em: www.revistafenix.pro.br

Furtado destacam: Emília Snethlage, zoóloga que coletou dados etnográficos e linguísticos dos indígenas Xipaya e Kuruaya; Rodolfo Schuller, estudioso dos indígenas que organizou a chamada Bibliografia Amazônica; Curt Nimuendajú, um dos mais importantes pesquisadores da temática indígena, marcante pela intensa convivência e utilização da língua nativa e representou, para Eduardo Galvão, de acordo com Maués, que

\footnotetext{
A pesquisa de campo, nos termos que hoje a concebemos, tornou-se com ele [...] uma realidade, em substituição às clássicas e longas viagens de exploração, em que o contato entre [os índios] e o pesquisador era muito abreviado e por isso mesmo orientado para aqueles aspectos mais aparentes do que então se chamava de "cultura material", de comportamentos aparentemente exóticos ou aberrantes, ou de uma embobinada preocupação pela mitologia (MAUÉS, 2011, p. 75).
}

Clifford Evans, Betty Meggers e Peter Hilbert, marcos importantes para os estudos arqueológicos na Amazônia com a análise de fragmentos escavados no arquipélago do Marajó, no Amapá e nas Ilhas Mexiana e Caviana; são alguns desses nomes que auxiliaram e deram continuidade aos ideais propostos por Emílio Goeldi no fim do século XIX e início do XX, tornando o museu uma referência dentro e fora do país.

\section{PARA ALÉM DO MUSEU PARAENSE EMÍLIO GOELDI: ANTROPOLOGIA E "UNIVERCIDADE"}

Como pôde ser observado nas seções anteriores, durante a segunda metade do século XIX e a primeira do século XX houve o período em que a Antropologia na Amazônia, e no Brasil, teve suas bases assentadas, sendo os museus etnográficos as grandes referências para a consolidação de um fazer antropológico no país, em especial, para o recorte deste trabalho, na Amazônia, por meio do Museu Goeldi.

Para além do MPEG, de acordo com Costa (2009, p. 742) e Maués (2011, p. 77), é criado o Instituto de Antropologia e Etnologia do Pará, em 1947, e a Faculdade de Filosofia, Ciências e Letras, em 1955, que depois foi incorporada à Universidade Federal do Pará. Isto é, os estudos antropológicos continuaram a ser desenvolvidos no Museu Goeldi - que a partir de 1955 teve em seu quadro o experiente pesquisador, já com doutorado, e um dos responsáveis pelo desenvolvimento destes estudos na 
Amazônia, Eduardo Galvão - mas também, a partir de então, com o aporte do campo acadêmico, tendo o nome de Napoleão Figueiredo como o mais relevante no contexto de uma Antropologia na academia.

Os estudos sobre etnologia indígena na Amazônia se fortaleceram a partir dos estudos de Nimuendajú - que pode considerado o primeiro etnólogo da Amazônia, sem esquecer, para citar duas, as contribuições de Lévi-Strauss e seus estudos sobre os Nambikuara e os Tupi-Kawahib, e de Roberto Cardoso de Oliveira e sua pesquisa sobre os Tükuna. Daí em diante, o nome de Eduardo Galvão, por meio do Museu Goeldi, ganha relevância na região. No entanto, apesar de os estudos etnológicos prevalecerem, o surgimento da Faculdade de Filosofia, Ciências e Letras e posteriormente sua incorporação à UFPA, abriram margem para a formação de novos antropólogos assim como para um enfoque mais urbano da Antropologia.

Nessa esteira da formação-consolidação da Antropologia e do fazer antropológico na Amazônia, em relação a um aspecto mais ligado a urbe, um dos primeiros e mais importantes trabalhos a serem apresentados acerca de uma Antropologia com enfoque urbano foi o da pesquisadora Anaíza Vergolino, em parceria com o já citado pesquisador, e também professor, Napoleão Figueiredo. O trabalho apresentado na VII Reunião da Associação Brasileira de Antropologia - ABA, realizada em Belém, no ano de 1966, e intitulado Alguns elementos novos para os estudos dos Batuques de Belém enfocava, segundo Costa (2009, p. 744), os espaços de ritos afroreligiosos enquanto parte da dinâmica sociocultural da cidade e campos densos para as pesquisas em Antropologia, o que, ainda segundo Costa, concede-lhe um ar de pioneirismo.

Entretanto, pensa-se que o ar de pioneirismo sugerido por Costa se restringe aos aspectos acadêmicos e metodológicos da pesquisa de Vergolino e Figueiredo, visto que dos enfoques supracitados, o reconhecimento dos terreiros enquanto parte importante para o aspecto sociocultural de Belém fora aludido pelo menos três décadas antes, por intelectuais engajados da época, entre eles Bruno de Menezes e Dalcídio Jurandir. Comentar-se-á acerca disto a posteriori.

No ano de 1971 a reforma universitária chegou ao Pará e com ela a criação da Universidade Federal, no modelo que temos hoje. Nesse período, segundo Maués (2011, p. 84), apenas Napoleão Figueiredo e Armando Bordalo da Silva faziam parte da cadeira de Antropologia, juntamente com seus assistentes, Anaíza Vergolino e Silva, 
Eneida Assis e Samuel Sá. A partir de então, com a abertura de editais para concursos, outros antropólogos - formados por Eduardo Galvão e Samuel Sá no Museu Paraense Emilio Goeldi - ingressaram na academia. Nomes como os de Maria Angélica MottaMaués, Raymundo Heraldo Maués, Romero Ximenes Ponte e Alexandre Ferreira da Cunha são de extrema importância para esta fase acadêmica da Antropologia na Amazônia, abrindo portas para outros que ingressaram posteriormente. Desta forma, contribuindo, desde então, para o desenvolvimento humano na/da Amazônia por meio da Antropologia e de seus múltiplos fazeres.

\section{DE VOLTA A UM POSSÍVEL COMEÇO: BRUNO DE MENEZES E SUA "ANTROPOLOGIA"}

Em 1893, nasceu Bruno de Menezes, de origem pobre, criado no bairro do Jurunas, na cidade de Belém, no Pará, em meio a embarcações e batuques, emergia, em seus territórios de vida, imagem das contradições de uma cidade rica para poucos e miserável para muitos. O primeiro trabalho foi como aprendiz de gráfico ainda muito jovem, período marcado por horas de trabalho a fio, pelo descaso e castigos, fatos que, entre outras experiências compartilhadas, provavelmente contribuíram para torná-lo um crítico ferrenho do sistema capitalista, levando-o a vivências anarquistas entre as décadas de 1910 a 1920, conforme aponta Figueiredo (2007).

Bruno era filho de "Seu" Dionísio, pedreiro, e Maria Balbina, dona de casa. Sua obra está situada em um intervalo de 40 anos, de 1920 a 1960, e neste período o Brasil e, mais especificamente, a Amazônia paraense, vivenciaram mudanças diversas, as quais não passaram impunes aos olhos do escritor, e, concomitantemente, a Antropologia na região buscava sua consolidação.

No início do século XX, Belém tinha se tornado um dos grandes centros escoadores da produção de látex para o resto do mundo, mas também se tornou importadora de modelos culturais europeus, principalmente o francês. As riquezas geradas pela produção da borracha proporcionaram, segundo Sarges (2010), um dos períodos mais intensos, cultural, econômica, social e urbanisticamente da história de uma das principais capitais amazônicas: a Belle Époque.

Nos anos de 1920, a cidade possuía rescaldos de sua bela época, no entanto, a dita decadência da Belle Époque proporcionou o surgimento de outras perspectivas, nas 
quais a marginalidade artística teve voz e vez. Bruno de Menezes vivenciou a transformação socioeconômica de Belém e isso marcou profundamente suas letras. Sua obra poética, primeiramente, fora fortemente influenciada pela estética simbolista - de la musique avant toute chose - no início da década de 1920, e que daria o tom em grande parte de sua obra literária. No entanto, aos poucos, a veia modernista pulsou mais forte. Para o professor Francisco Paulo Mendes, Bruno de Menezes foi o grande arauto do estilo modernista na região amazônica, destacando um de seus primeiros versos, no poema Arte Nova, ainda no ano de 1920, antes da Semana de 22, no qual o poeta diz: "Eu quero uma arte original" (1993a).

De acordo com a fala do historiador do Modernismo, Joaquim Inojosa, no ano de 1972, por conta da Festa Paraense do Livro, Belém do Pará teria sido a terceira capital do país a entrar em contato com o movimento modernista no Brasil, por isto a relevante alcunha de introdutor do Modernismo na Amazônia a Bruno de Menezes (1994). Por volta de 1923, o escritor viria a alcunhar seus amigos dos encontros no terraço do Grande Hotel em Belém (Edgard Proença, Eustáchio Azevedo, Jacques Flores, Muniz Barreto, entre outros) de Vândalos do Apocalipse. Organizou-se a partir de então a Associação dos Novos e fundou-se a revista Belém Nova, mola propulsora e propagadora do modernismo na região.

Bruno foi um lutador incansável, homem ligado diretamente às cooperativas relacionadas à terra, preocupado com as desigualdades sociais existentes, uma mente com fervor revolucionário que visibilizou negros, prostitutas e flagelados, denunciando as iniquidades por meio de seus escritos, quebrando o paradigma de se falar pela classe menos favorecida, pois em Bruno a margem tem voz, história e importância.

Seu espírito de putirum $^{2}$ e seu fervor pelo cooperativismo fizeram Bruno se tornar Diretor do Departamento do Estado do Pará de Cooperativismo, cargo pelo qual se aposentou em 1955. No ano anterior, 1954, o intelectual havia ingressado no Instituto Histórico e Geográfico do Pará.

Bruno foi um exímio folclorista. Estudioso que pertenceu, inclusive, à Comissão Paraense de Folclore, trabalhando com as manifestações artísticas de cunho popular e lecionando a disciplina Folclore por meio do SENAC/ Departamento

\footnotetext{
2 Putirum, termo indígena que significa comunhão; mutirão; construir junto.
} 
Regional do Pará. Note-se que o escritor e pesquisador Bruno de Menezes ${ }^{3}$ não era, de modo algum, canônico. Bruno valorizava o que provinha das margens, fazendo referência com mestria desta realidade marginal na literatura. Alonso Rocha, principal biógrafo de Bruno, tece um interessante comentário acerca das vivências religiosas e "folclóricas" do autor:

A infância passou-a na estância coletiva "A Jaqueira", no bairro do Jurunas, livre e solto, convivendo e admirando os seus valentes desordeiros, os capoeiras, os manejadores de navalha, os embarcadiços, as mulatas e trescalantes; acompanhando nos ombros largos de seu pai o círio de Nazaré, gola azul, gorro de marinheiro de fitas pretas e letras douradas, pisoteando, adolescente nas saídas festivas de Boi-Bumbá de seu padrinho Miguel Arcanjo, sob os olhares carinhosos de sua mãe Balbina e a proteção de João Golemada, maranhense, valente na defesa de seu bando, quando a policia ainda não havia proibido os "bois" saírem de seus currais para os tradicionais encontros (ROCHA, 1994, p. 09).

João Carlos Pereira (1994, p. 80-81), faz uma afirmação interessante para o propósito desta pesquisa, reconhecendo a importância de Bruno para um certo campo antropológico, como era considerado o Folclore: "Sua literatura esteve marcada por esse ramo da Antropologia, que serviu de força propulsora à sua criação artística".

Bruno de Menezes fora um homem multifacetado ao longo de sua vida. Tanto pelos ofícios em que laborou quanto pela variedade de escritos que produziu. Este ser fragmentado que Bruno mostrou ser é um dos aspectos mais importantes a serem destacados neste trabalho. Esta fragmentação, para Stuart Hall, significa que

El sujeto, previamente experimentado como poseedor de una identidad estable y unificada, se está volviendo fragmentado; compuesto, no de una sola, sino de varias identidades, a veces contradictorias y sin resolver. En correspondencia con esto, las identidades que componían los paisajes sociales "allí afuera" y que aseguraban nuestra conformidad subjetiva com las "necesidades" objetivas de la cultura se están rompiendo como resultado del cambio estructural e institucional (HALL, 2010, p. 365).

\footnotetext{
Bruno também teve seus trabalhos e suas críticas reconhecidos. Fez parte da Academia Paraense de Letras, da qual chegou a ser presidente, ocupando a cadeira número 32, e ganhou prêmios referentes aos seus escritos, no Pará e fora do estado. Suas obras publicadas foram: Poesia: Crucifixo (1920); Bailado lunar (1924); Poesia (1931); Batuque (1931); Lua sonâmbula (1953); Poema para Fortaleza (1957); Onze sonetos (Prêmio Cidade São Jorge dos Ilhéus - Bahia - 1960); Folclore: Boi Bumbá Auto Popular (1958); São Benedito da Praia - Folclore do Ver-o-Peso (1959); Estudo Literário: À margem do "Cuia Pitinga" (sobre o livro de Jacques Flores - 1937); Ficção: Maria Dagmar (novela 1950); Candunga (romance - Prêmio "Estado do Pará" - 1954).
} 
O intelectual paraense obteve destaque no cenário cultural, na primeira metade do século XX em Belém, não apenas pela qualidade de suas obras literárias, mas também por sua liderança em grupos de intelectuais e pelo seu engajamento políticosocial. Para além de introdutor do Modernismo na Amazônia, na busca incessante por mudanças, Bruno vivenciou o contexto da "higienização" da cidade de Belém, como herança elitista do que restara da Belle Époque, traço de um período em que, embasados pela ciência na busca pela civilidade, vários intendentes brasileiros, sob uma ótica eurocentrada, iniciaram a "limpeza cultural" de suas cidades, atingindo principalmente as camadas mais pobres e suas respectivas manifestações culturais. A repressão contra os terreiros e contra a saída dos bois bumbás fizeram parte da "limpeza" feita em Belém e diante disso, Bruno, juntamente com outros intelectuais, ergueu voz ante a repressão do poder público contra tais manifestações periféricas.

Neste período, a luta pela liberdade de expressão no que tange aos cultos de matriz africana ganha apoio dos intelectuais (literatos, folcloristas etc) os quais se organizaram e se engajaram nesta questão, a partir de 1938, sendo base para algo mais amplo vivido em nível nacional nas décadas seguintes, principalmente 1940, 1950 e 1960. É o contexto, também, da consolidação de um fazer antropológico na região amazônica, a partir de estudos que ampliavam a noção de formação cultural da Amazônia, pondo a questão do negro em destaque, junto com a questão indígena, como as pesquisas de Vergolino-Silva e Figueiredo, autores de Alguns elementos novos para os estudos dos Batuques de Belém e Vicente Salles, autor da obra O negro no Pará, diretamente influenciado por Bruno de Menezes e Edison Carneiro, sendo que Salles conheceu este último por intermédio do primeiro. Corroboram, em termos atuais, para o desvelamento da contribuição negra à formação sociocultural da Amazônia, os dados fornecidos por Bezerra Neto, afirmando que

Desde a segunda metade do século XVIII, na região de Belém, em seu espaço urbano e cercanias, concentrava-se boa parte da população escrava da província do Pará. Em 1793, por exemplo, viviam 8.573 habitantes, sendo 4.423 brancos $(51,6 \%), 3.051$ escravos negros $(35,6 \%)$ e 1.099 pretos, índios e mestiços livres (12,8\%) (NETO, 2002, p. 221).

Nesse sentido, Bruno, juntamente com outros intelectuais ativistas, entre eles Dalcídio Jurandir, companheiro de Academia do Peixe Frito, assinou, em 1938, um 
Disponível em: www.revistafenix.pro.br

manifesto contra o fechamento dos terreiros, destacando a importância sociocultural de tal prática religiosa para a dinâmica da cidade.

Desta maneira, a década de 1930 seria, no Brasil, o grande marco do controle cultural estabelecido pelo poder público central e seguido por seus respectivos interventores. Em Belém, Bruno lançara Batuque, 1931, antes da ordem de fechamento dos terreiros. No entanto, de acordo com Leal,

Parte de seu conteúdo, no entanto, voltou a circular na imprensa local após o início da campanha de repressão de 1937, o autor visava fundamentar a importância da contribuição negra para a Amazônia. Apesar de todos os poemas tratarem da temática negra, - Batuque, - Pai João e - Mãe preta, entre outros, se destacam por abordar diretamente a experiência relacionada à escravidão e à resistência (LEAL, 2011, p. 17).

Para ilustrar o destaque dado por Leal, segue abaixo o poema Pai João enquanto marca da rexistência ${ }^{4}$ ante a repressão elitista.

Pai João sonolento bambo na pachorra da idade cisma tempo de ontem.

De olhos vendo o passado recorda o veterano

a vida brasileira que ele viu e gozou e viveu!

Mãe Maria contou que o pai dele era escravo...

Moleque sagica e teso, destro e afoito num rolo,

Pai João teve fama da capoeira e navalhista.

- Eita!... era o pé comendo, quando a banda marcial saía à rua, com tanto soldado de calça encarnada.

E rabo-de-arraia, cabeçada na polícia, xadrez, desordens, furdunço no cortiço e o ronco e o retumbo do zonzo som molengo do carimbó.

De amores... uma anágua de renda engomada, um cabeção pulando nos bicos duns peitos, umas sandálias brancas bem na pontinha dum pé.

E o rebolo bolinante dos quartos roliços da Chica Cheirosa...

E a guerra do Paraguai! Recrutamento!

Gurjão! Osório! Duque de Caxias! Itororó! Tuiutí! Laguna!

E não sabia nem o que era monarquia!

4 Utilizo o neologismo rexistência, ao se tratar de Bruno, por perceber que o intelectual teve sua existência extremamente ligada à resistência das minorias subalternizadas diante da opressão das elites locais. 


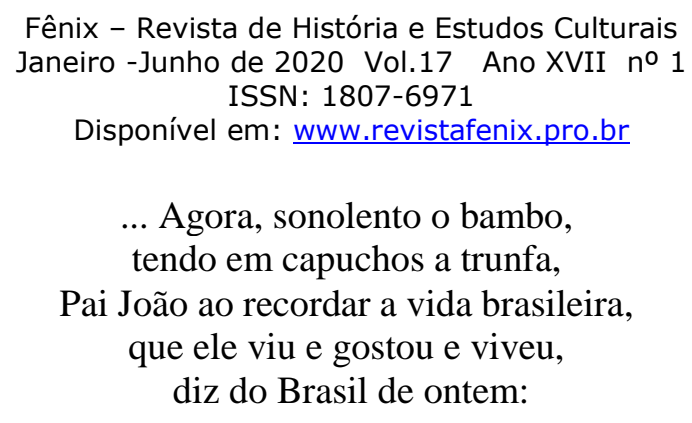

O crítico Dante Costa faz uma interessante observação acerca da obra Batuque, de Bruno, ao afirmar que o literato da Amazônia paraense

É um poeta forte e desigual, menos sutil que Raul Bopp e menos gracioso que o Jorge de Lima dos poemas negros. Porém, nenhum dos dois, talvez, tenha realizado transposição mais fiel das vivências do negro no Brasil, do fato folclórico, da realidade que não interessa apenas ao crítico literário, mas também e principalmente ao sociólogo, ao estudioso dos hábitos e costumes, ao etnógrafo do negro brasileiro (Jornal “O Dia”, Rio de Janeiro, 1955; COSTA, 1993, pp. 104-105).

Neste contexto de rexistência, outra manifestação apreciada e observada por Bruno foi o boi bumbá. No ano de 1905, quando o menino Bruno contava apenas 12 anos, houve a proibição da saída dos bois em Belém, pelo então intendente Antônio Lemos, devido às ações violentas cometidas, de acordo com o poder municipal, pelos brincantes de bois rivais, resultando na morte do brincante João Golemada, o dito protetor de Bruno de Menezes pelas ruas da periferia. Em 1915 a manifestação volta a ser liberada, mas repleta de normas a partir de então, os chamados códigos de postura. Tanto que em 07/06/1940, na portaria 152, de acordo com Leal, estava escrito

\footnotetext{
que aos ditos bumbás e "cordões" não sejam, em absoluto, concedidas licenças para exibições nas ruas ou praças desta Capital, mas exclusivamente nas respectivas sedes, em casa de famílias ou em outras qualquer[sic] casas de diversões, devendo, porém, os seus comparsas seguirem para o local da exibição, dispersos e não em agrupamentos. (Polícia civil - Portaria 152, jornal A Vanguarda, 08 de junho de 1940, p. 02; LEAL, 2011, p. 74).
}

Em 1951, Bruno de Menezes, bastante envolvido há tempos com as questões culturais da Amazônia, envia, por meio da Comissão de Folclore do Pará, ao $1^{\circ}$ Congresso de Folclore Brasileiro, um trabalho que teria boa repercussão no meio, sendo inclusive indicado à publicação nos anais do referido Congresso $A$ evolução do Boi 
Disponível em: www.revistafenix.pro.br

Bumbá como forma de teatro popular. O trecho a seguir traz uma parte do parecer emitido pela comissão do Congresso:

O autor ocupa-se do auto popular do Boi Bumbá, que se realiza no estado paraense. Tentando interpretá-lo, de início, nas suas raízes psicológicas e mesmo sociais, desenvolve, de certa maneira, conceitos emitidos por Nina Rodrigues, Manoel Querino, Arthur Ramos. (...) Concluímos, após a leitura desse bem elaborado trabalho, que o mesmo deva ser publicado nos Anais do Congresso, pois muitos dados e vários conceitos ali emitidos constituem elementos valiosos para o necessário estudo que vem se fazendo em torno desse interessantíssimo aspecto da demologia brasileira (CONGRESSO, 1972, p. 15).

Entretanto, o próprio autor admite que o trabalho ainda necessitava de mais apuro e uma certa organização didática para o acesso do público leitor.

O resultado do reconhecimento da necessidade de uma certa organização, pelo próprio autor, foi a publicação, em 1958, do livro Boi Bumbá: Auto Popular. Sob a ótica de Bruno, a partir das observações e entrevistas feitas, bem como das referências lidas, o bumbá seria uma manifestação tradicional com características marcadamente "afroameríndias", juntamente, a posteriori, com os elementos do homem branco. Nesse sentido, o boi bumbá seria, sob o viés desta pesquisa, uma manifestação que materializaria o que a teórica pós-colonial Mary Louise Pratt chama de "zona de contato", que segundo a própria autora seria "uma tentativa de se invocar a presença espacial e temporal conjunta de sujeitos anteriormente separados por descontinuidades históricas e geográficas cujas trajetórias agora se cruzam” (1999, p. 32).

Canclini (2009, p. 143), dialoga com Pratt, sob uma perspectiva antropológica, não observando a cultura por ela mesma, mas compreendendo que há imbricações simbólicas, econômicas surgidas da diversidade de comportamentos e representações, o que ele chama de um estudo intercultural. No que diz respeito ao boi bumbá do Pará, Bruno percebeu que negros, indígenas e brancos pobres compunham a dinâmica da manifestação.

O folclore junino do Bumbá deveria ocupar uma classificação especial, norteada para o teatro popular. Auto pastoril de sobrevivências totêmicas, sofrendo atuais modificações, mesclado do patriarcalismo colonial com a catequese do gentio, o curandeirismo africano, o primitivismo agrícola, a vida chucra nas fazendas de gado, as diversões permitidas nas senzalas, o Boi Bumbá teria seus 
fundamentos tradicionais na aculturação afro-ameríndia, inevitável ao branco ruralista (MENEZES, 1972, p. 23).

Interessante não é apenas destacar o boi bumbá enquanto materialização de uma zona de contato, com fortes traços de interculturalidade, mas também observar o boi bumbá enquanto prática de rexistência.

Pratt, destaca três termos que norteiam seu texto: zona de contato, anticonquista e auto-etnografia. Abordou-se aqui, de forma breve, o primeiro, a partir de agora a auto-etnografia vem à discussão. Na perspectiva de Pratt (1999, p. 33), o termo se caracteriza pela resposta ou diálogo do colonizado em relação às representações oriundas da metrópole. Em Boi Bumbá, Bruno percebe que

(...) tanto Pai Francisco, a Mãe Catirina (assim se pronuncia no Pará), o compadre Cazumbá, e a companheira deste, Mãe Guimá, sugerirem quando encarnam a parte irônica e dramática do Bumbá, preservarem a sua linhagem, a sua ascendência real e moral, entre os que também teriam sido capturados, pertencentes a sua nação (MENEZES, 1972, p. 24).

Para Bruno, essa dinâmica de alguns personagens, reflete o aspecto burlesco, cômico da encenação, que intenta expor o amo ao ridículo e afirmar sua linhagem real. Ou seja, as personagens assimilam traços do colonizador como forma de rexistir à opressão deste na dinâmica do Boi. Na ótica de Pratt, fazendo-se as devidas analogias, esta característica das personagens seria a comprovação de um fazer auto-etnográfico, elaborando uma dinâmica de resistência a partir da apropriação do léxico metropolitano.

Tanto Batuque quanto Boi Bumbá: Auto Popular materializam um olhar etnográfico sobre o fazer-se pesquisador de Bruno de Menezes. Nas palavras do próprio autor, em relação à segunda obra: "De um cunho evidentemente de demopsicologia etnográfica, o Bumbá, de que fala este trabalho, constitui uma variante à parte dos chamados bumba-meu-boi do Nordeste.” (1972, p. 32)

Nesse sentido, pôde-se observar anteriormente, tanto na crítica em relação ao Batuque feita por Dante Costa quanto no parecer acerca do texto enviado pelo intelectual ao Congresso Brasileiro de Folclore, - em que fora percebido pelo avaliador que o autor estava ancorado em teorias vigentes naquele contexto, destacando Nina Rodrigues e Arthur Ramos - que empiria e teoria estão latentes na escrita de Bruno. Tal fato corrobora com os dizeres de Mariza Peirano (2006, p. 07) ao afirmar que "a teoria é o par inseparável da etnografia”. 
Desta maneira, brevemente, a partir dos escritos de e sobre Bruno de Menezes, nota-se que sua vivência, suas andanças pelas ruas de Belém, deram-lhe o know-how de se tornar, certamente, uma das principais fontes de informação sobre a cultura paraense em sua época. Como afirma Vicente Salles, no título de um texto acerca do literato em questão: "Bruno de Menezes era o folclore". Aliás, Vicente Salles teve em vida uma relação muito próxima com Bruno de Menezes. Segue um trecho interessante para o propósito deste trabalho.

Minha memória é toda Bruno de Menezes portador de folclore. Quando adolescente, morei na rua Santarém, na Cidade Velha. Era tempo difícil, 13 anos, menino chegado do interior. Duas pessoas então marcaram minha entrada na vida de adulto, precocemente iniciada na necessidade de trabalhar: o sapateiro Dagoberto Lima, "seu" Lima, que me levou à utopia socialista, emprestando-me livros e jornais comunistas que lia avidamente, de um lado; o poeta Bruno de Menezes, nosso quase vizinho, que me levou aos subúrbios a ver batuques, pássaros e bumbás, doutro lado. Os dois tinham muito em comum, o sapateiro e o poeta, mas agiam de modo diferente: o sapateiro me intelectualizava; o poeta me ensinava o ofício de observador da vida popular (SALLES, 1993b, p. 15). [destaque nosso]

Para Oliveira (2006, p. 31) o escrever é uma parte indissociável do pensamento, baseado em um olhar e em um ouvir atentos que constituem a percepção da realidade centrada na pesquisa empírica. Pensa-se que o que Bruno viu, ouviu e escreveu denotam um fazer etnográfico, ou, ousa-se dizer para o contexto desta pesquisa, de acordo com Pratt (1999), auto-etnográfico, por falar de si, de sua gente, de sua cidade e da realidade reconstruída em seus textos. Estabelecendo a devida analogia com os dizeres de Gilberto Velho (2013, p. 25): “A Antropologia, tradicionalmente, tem estudado os 'outros' e eu me propus a estudar o 'nós"'.

\section{CONSIDERAÇÕES FINAIS}

Sendo assim, pôde-se observar que ao cruzarmos os caminhos da Antropologia na Amazônia com os caminhos das experiências de Bruno de Menezes as preocupações sociais emergem. O literato, enquanto intelectual engajado e com uma vasta leitura, e a Antropologia com seus métodos e sua institucionalização. O poeta e a ciência almejando objetivos semelhantes, mas seguindo por rumos diferentes, antropólogos/etnógrafos de si e dos outros. 
Desta maneira, neste trabalho se buscou elucidar, de maneira breve, a possibilidade de ampliação, ressignificação do fazer literário de Bruno de Menezes, dando amplitude ao estudo referente a um Bruno que não foi apenas literato engajado, mas um etnógrafo das minorias marginalizadas, possibilitando, por meio de sua antropoética, um ecoar de vozes obnubiladas ao longo do tempo.

\section{REFERÊNCIAS BIBLIOGRÁFICAS}

BEZERRA NETO, J. M. Histórias urbanas de liberdade: escravos em fuga na cidade de Belém, 1860-1888. Revista Afro-Ásia, nº 28, UFBA, 2002, pp.221-250.

CANCLINI, N. G. A globalização da antropologia depois do pós-modernismo. In: Diferentes, desiguais e desconectados: mapas da interculturalidade. Trad. Luiz Sérgio Henriques. $3^{\text {a }}$ ed. Rio de Janeiro. Editora UFRJ, 2009, pp. 129-149.

COSTA, A. M. D. da. Pesquisas antropológicas urbanas no "paraíso dos naturalistas". Revista de Antropologia, USP, São Paulo: 2009, pp. 735-761.

FERREIRA, L. M. "Ordenar o Caos": Emílio Goeldi e a Arqueologia Amazônica. Boletim do Museu Paraense Emílio Goeldi. Ciências Humanas 4 (1), 2009, pp. 71-91. FIGUEIREDO, A. M. Arte, literatura e revolução: Bruno de Menezes, anarquista, 19131923. In FONTES, Edilza Joana de Oliveira \& BEZERRA NETO, José Maia (orgs.). Diálogos entre Literatura, História e Memória. Belém: Paka-Tatu, 2007, pp, 293307.

HALL, S. Sin garantías: Trayectorias y problemáticas en estudios culturales. Editores: Eduardo Restrepo, Catherine Walsh y Víctor Vich. Colômbia, Peru y Ecuador. Instituto de estudios sociales y culturales Pensar; Universidad Javeriana Instituto de Estudios Peruanos; Universidad Andina Simón Bolívar; Envión Editores, 2010.

LEAL, L. A. P. Nossos intelectuais e os chefes de mandinga: repressão, engajamento e liberdade de culto na Amazônia (1937-1951). Tese de Doutorado. Salvador: UFBA, 2011.

MENEZES, B. de. Boi Bumbá: Auto Popular. $2^{\text {a }}$ ed. Belém. Imprensa Oficial do Estado do Pará. 1972.

Obras Completas, v.1, Poesia. Belém: SECULT, 1993a. .Obras Completas, v.2, Folclore. Belém: SECULT, 1993b.

MAUÉS, R. H. Memórias da Antropologia da Amazônia ou como fazer ciência no "paraíso dos etnólogos". In Encontro de Antropologia: homenagem a Eduardo Galvão. Orgs. Sônia Barbosa Magalhães; Isolda Maciel da Silveira; Antônio Maria de Souza Santos. Manaus: EDUA \& MPEG, 2011.

OLIVEIRA, A.E.de. \& FURTADO, L.G. As Ciências Humanas no Museu Paraense Emílio Goeldi: 128 Anos em Busca do Conhecimento Antropológico na Amazônia. Revista Brasileira de Informação Bibliográfica em Ciências Sociais - BIB - Rio de Janeiro, $\mathrm{n}^{\circ} 39,1^{\circ}$ semestre, 1995, pp. 103-109.

OLIVEIRA, R. C. de. O trabalho do antropólogo. $3^{\text {a }}$ ed. São Paulo: Unesp, 2006. PEIRANO, M. A teoria vivida e outros ensaios de antropologia. Rio de Janeiro: Zahar, 2006. 
PIZARRO, A. Amazônia: as vozes do rio - imaginário e modernização. Tradução Rômulo Monte Alto. Belo Horizonte: Editora UFMG, 2012. Imaginario y discurso: la Amazonía. In: X Encontro Regional da ABRALIC - Sentidos dos lugares. Anais do X Encontro Regional da ABRALIC, 2005, pp. 130-151.

PRATT, M. L. Os olhos do império: relatos de viagem e transculturação. Trad. Jézio Hernani Bonfim Gutierre. Bauru-SP: EDUSC, 1999.

ROCHA, A. et al. Bruno de Menezes ou a sutileza da transição: Ensaios. Belém: CEJUP, 1994.

SALZANO, F. M. A Antropologia no Brasil: é a interdisciplinaridade possível? Amazônica Revista de Antropologia. Belém, v.1, n.1, sem 1. 2009, pp. 12-27.

SARGES, M. de N. Belém: Riquezas Produzindo a Belle Époque (1870-1912). $3^{\text {a }}$ ed. Belém: Paka-Tatu, 2010.

SCHWARCZ, L. M. "Os museus etnográficos brasileiros: 'polvo é polvo, molusco também é gente"'. In $\mathbf{O}$ espetáculo das raças: cientistas, instituições e questão racial no Brasil - 1870-1930. São Paulo: Companhia das Letras, 2010, pp. 67-96.

VELHO, G. Um antropólogo na cidade: ensaios de Antropologia Urbana. Orgs. Hermano Vianna; Karina Kuschnir; Celso Castro. Rio de Janeiro: Zahar, 2013. 